\title{
Caution in co-administration of aripiprazole and lithium in patients with learning disability
}

\begin{abstract}
Bipolar disorder is a complicated syndrome. The first line of bipolar disorder treatment is pharmaco-therapy. Aripiprazole is a safe and effective medication in acute phase of bipolar disorder. This report is about a patient who suffers from comorbidity of bipolar mood disorder and learning disability. The patient developed with extra pyramidal symptom in combination of aripiprazole and lithium in doses lower than therapeutic dosages. This finding can be explained by susceptibility of a traumatized brain to neurological side effects of antipsychotics and drug interactions.
\end{abstract}

Volume 5 Issue 6 - 2017

\author{
Arvin Hedayati \\ Assistant Professor, Department of Psychiatry, Shiraz University \\ of Medical Sciences, Iran \\ Correspondence: Arvin Hedayati, Assistant Professor, \\ Psychiatrist, fellowship of psychosomatic medicine Research \\ Center for Psychiatry and Behavioral Sciences, Department \\ of Psychiatry, Shiraz University of Medical Sciences, School of \\ Medicine, Shiraz, Iran, Tel 098938I079746, \\ Email hedayatia@sums.ac.ir
}

Received: August 01, 2017| Published:September 13, 2017

\section{Introduction}

Bipolar disorder is a complicated syndrome with multifactorial etiology such as neuro-endocrine, genetic, and environmental factors. ${ }^{1}$ The first line treatment of bipolar disorder is pharmaco-therapy. ${ }^{2}$ In acute phase of mania, lithium, anticonvulsants ${ }^{3}$ and antipsychotic agents are suitable for symptom management. ${ }^{4}$ Aripiprazole as a third generation antipsychotic, is a partial agonist of the dopamine D2 receptor, a partial agonist of the serotonin 5- $\mathrm{HT}_{1 \mathrm{a}}$ receptor, and antagonist of the $5 \mathrm{HT}_{2 \mathrm{~A}}$ receptor sites. ${ }^{5}$ Aripiprazole has been defined as a dopamine system stabilizer. ${ }^{6}$ Due to its unique psychopharmacological profile the hypo-dopaminergic state is limited by this medication. Aripiprazole was approved by the FDA in 2004 for treatment of bipolar disorder. ${ }^{7}$ An important meta-analyses which was designed by Dian-JengLi and co-authors confirmed the efficacy or safety of aripiprazole in manic episodes. ${ }^{8}$

There are several studies that show long-term administration of aripiprazole in combination to lithium or valproate in bipolar mania is well tolerated and safe and this improvement in functioning is maintained. ${ }^{9,10}$ One of the side effects of aripiprazole is akatasia. ${ }^{11}$ The frequency of occurrence of other extra pyramidal symptomrelated events such as acute dystonia, parkinsonian syndrome, akathisia, akinesia, rabbit syndrome, tardive dyskinesia or neuroleptic malignant syndrome in short-term, and in long-term, and in patients with schizophrenia or bipolar mania is similar in both the placebo and the aripiprazole-treated groups. ${ }^{11}$

\section{Case report}

The patient was 30year old single lady, she couldn't finish primary school. She lives with her mother and could only do simple tasks such as individual care. In the other word she was a case of learning disability. Who came with increased energy, increased activity level, risky behaviors such as involvement in sexual contact, paranoid delusion about her neighbor and sever agitation and aggression. These symptoms began about 2 month's prior admission. This was the first episode of illness. Till now she never experienced depressive, hypomanic or psychotic episodes. All of the work ups such as biochemistry evaluation, thyroid function test and brain imaging was done and no abnormality was detected. With impression of Bipolar disorder type I, pharmacotherapy began. She received lithium $150 \mathrm{mg}$ QHs and Aripiprazole 5mg QD. The therapeutic response in management of agitation and control of hyperactivity was dramatic. During first week of therapy, agitation and aggression improved and paranoid delusions became shaky.

$8^{\text {th }}$ day of admission she became febrile (38C axillary) and she developed with tremor, sialorrhea and drowsiness. All of the medications became hold and IV hydration started. The most important differential diagnosis was neuroleptic malignant syndrome. In lab data, white blood cells and creatine phosphokinase were normal. Vital signs were stable and no change in blood pressure or pulse rate were detected. After hydration the patient became afebrile. So neuroleptic malignant syndrome ruled out. The other differential diagnosis was extrapyramidal symptom. By conservative management such as administration of Inderal 10mg PO BID, hydration, and supportive care after 4days the tremor and sialorrhea completely improved.

At this time the patient was oriented to time, place and person. But she was restless and elevated mood was obvious. She reported auditory and visual hallucination. So management of symptoms with antipsychotic was necessary. This time quetiapine with dosage of $12.5 \mathrm{mg}$ PO BID began for the patient. After 10days the psychotic symptoms disappeared and mood swing became partially controlled. Quetiapine 25mg po BID were effective for control of symptoms and the patient discharged from the psychosomatic ward at the end of $38^{\text {th }}$ day of admission. 


\section{Discussion}

Although akathisia is not uncommon in patients receiving aripiprazole, other extrapyramidal side effects of this drug were equivalent to placebo. ${ }^{11}$ Patients who suffers from learning disability, benefit from atypical antipsychotics for management of agitation and aggression..$^{12}$ In these patients, comparison of typical and atypical antipsychotics, show that akatasia is more prevalent with first generation antipsychotics, but no differences is reported in happening of dystonia and Parkinsonism/Dyskinesia. ${ }^{13}$ It means that both groups of antipsychotics can cause parkinsonism. Among atypical antipsychotics, the least prevalence of Parkinsonism is reported with Aripiprazole. ${ }^{14}$

When you search drug interactions between Aripiprazole and lithium, it is reported that in patients with normal learning function this combination can lead to dizziness, drowsiness, confusion, and difficulty concentrating. Elderly, may experience dysfunction in thinking, judgment, and motor coordination..$^{15}$ In the other word this combination is defined as a safe and effective treatment for management of acute mania in bipolar disorder. ${ }^{16-18}$ In patients who suffers from schizophrenia or schizoaffective disorder, therapeutic doses of lithium had no clinically significant effects on the pharmacokinetics of aripiprazole. ${ }^{19}$

Although animal studies present the effective role of antipsychotics on cognitive function in cases with brain injury. ${ }^{20}$ There are case reports that show more sever neurologic side effects with aripiprazole in patients with brain injury and learning disability. ${ }^{21,22}$ These similar findings can be explained by susceptibility of a traumatized brain to neurological side effects of antipsychotics and drug interactions. This problem even can present in cases who use medications with lesser than therapeutic dosages. Of course designing of cross sectional and clinical trial studies can help us to know more about the adverse effect of medications in patients with learning disorders.

\section{Acknowledgements}

None.

\section{Conflict of interest}

The author declares no conflict of interest.

\section{References}

1. Hawton K, Sutton L, Haw C, et al. Suicide and attempted suicide in bipolar disorder: a systematic review of risk factors. $J$ Clin Psychiatry. 2005;66(6):693-704.

2. Chatterton ML, Stockings E, Berk M, et al. Psychosocial therapies for the adjunctive treatment of bipolar disorder in adults: network meta-analysis. Br J Psychiatry. 2017;210(5):333-341.

3. Duffy A, Patten S, Goodday S, et al. Efficacy and tolerability of lithium in treating acute mania in youth with bipolar disorder: protocol for a systematic review. Int J Bipolar Disord. 2017;5(1):22.

4. Correll CU, Yu X, Xiang Y, et al. Biological treatment of acute agitation or aggression with schizophrenia or bipolar disorder in the inpatient setting. Ann Clin Psychiatry. 2017;29(2):92-107.

5. Cutler AJ, Marcus RN, Hardy SA, et al. The efficacy and safety of lower doses of aripiprazole for the treatment of patients with acute exacerbation of schizophrenia. CNS Spectr. 2006;11(9):691-702.
6. Levine M, Traub S, Burns MJ. The pharmacology and toxicology of aripiprazole. Internet J Med Toxicol. 2004;7:5.

7. Tuplin EW, Holahan MR. Aripiprazole, a drug that displays partial agonism and functional selectivity. Curr Neuropharmacol. 2017.

8. Li DJ, Tseng PT, Stubbs B, et al. Efficacy, safety and tolerability of aripiprazole in bipolar disorder: An updated systematic review and metaanalysis of randomized controlled trials. Prog Neuropsychopharmacol Biol Psychiatry. 2017;79(Pt B):289-301.

9. Vieta E, Owen R, Baudelet C, et al. Assessment of safety, tolerability and effectiveness of adjunctive aripiprazole to lithium/valproate in bipolar mania: a 46-week, open-label extension following a 6-week double-blind study. Curr Med Res Opin. 2010;26(6):1485-1496.

10. Yatham LN, Fountoulakis KN, Rahman Z, et al. Efficacy of aripiprazole versus placebo as adjuncts to lithium or valproate in relapse prevention of manic or mixed episodes in bipolar I patients stratified by index manic or mixed episode. J Affect Disord. 2013;147(1):365-372.

11. Bernagie C, Danckaerts M, Wampers M, et al. Aripiprazole and acute extrapyramidal symptoms in children and adolescents: a meta-analysis. CNS drugs. 2016;30(9):807-818.

12. Tsakanikos E, McCarthy J. Handbook of psychopathology in intellectual disability: Research, practice, and policy, autism and child psychopathology series. New York, USA: Springer Science + Business Media; 2013. p. 307-324.

13. Bowring DL, Totsika V, Hastings RP, et al. Prevalence of psychotropic medication use and association with challenging behaviour in adults with an intellectual disability. A total population study. J Intellect Disabil Res. 2017;61(6):604-617.

14. Sharma A, Sorrell JH. Aripiprazole-induced parkinsonism. International clinical psychopharmacology. 2006;21(2):127-129.

15. https://www.drugs.com/drug-interactions/abilify-withlithium-233-109-1477-0.html

16. Keck PE, Calabrese JR, McQuade RD, et al. Aripiprazole Study Group. A randomized, double-blind, placebo-controlled 26-week trial of aripiprazole in recently manic patients with bipolar I disorder. J Clin Psychiatry. 2006;67(4):626-637.

17. Sachs G, Sanchez R, Marcus R, et al. Aripiprazole Study Group. Aripiprazole in the treatment of acute manic or mixed episodes in patients with bipolar I disorder: a 3-week placebo-controlled study. $J$ Psychopharmacol. 2006;20(4):536-546.

18. Vieta E, T'joen C, McQuade RD, et al. Efficacy of adjunctive aripiprazole to either valproate or lithium in bipolar mania patients partially nonresponsive to valproate/lithium monotherapy: a placebo-controlled study. Am J Psychiatry. 2008;165(10):1316-1325.

19. Citrome L, Josiassen R, Bark N, et al. Pharmacokinetics of aripiprazole and concomitant lithium and valproate. J Clin Pharmacol. 2005;45(1):89-93.

20. Phelps TI, Bondi CO, Mattiola VV, et al. Relative to Typical antipsychotic drugs, aripiprazole is a safer alternative for alleviating behavioral disturbances after experimental brain trauma. Neurorehabil Neural Repair. 2017;31(1):25-33.

21. Palakurthi HB, Parvin MM, Kaplan S. Neuroleptic malignant syndrome from aripiprazole in an agitated pediatric patient. Clin Neuropharmacol. 2007;30(1):47-51.

22. Zaidi SH, Faruqui RA. Aripiprazole is associated with early onset of tardive dyskinesia like presentation in a patient with $\mathrm{ABI}$ and psychosis. Brain Inj. 2008;22(1):99-102. 